REVIEW ARTICLE

\author{
J.L. Bykowski \\ W.H.W. Wong
}

\section{Role of Facet Joints in Spine Pain and Image- Guided Treatment: A Review}

\begin{abstract}
SUMMARY: Chronic low back and neck pain remain prevalent medical concerns, with much debate regarding the effective evaluation and treatment. Facet disease has been implicated as a source of axial nonradiating low back pain. We discuss patient evaluation, the role of imaging, current and emerging image-guided therapies for facet-related pain, and the increasing importance of outcomerelated research in this arena.
\end{abstract}

ABBREVIATION: RFA = radio-frequency ablation l: has been long understood that facet joint degeneration can result from abnormal motion associated with disk degeneration $^{1,2}$ as well as arthritis, similar to that seen in other synovial joints. ${ }^{3}$ Proposed pain mechanisms include capsular stretch, entrapment of synovial villi between the articular surfaces, nerve impingement by osteophytes, and release of inflammatory factors. ${ }^{2,4,5}$ The facet joints have been implicated in $15 \%-$ $45 \%$ of cases of axial low back pain ${ }^{6-8}$ and $40 \%-55 \%$ of cases of chronic neck pain, without disk herniation. ${ }^{9,10}$

Early investigations demonstrated that pain could be generated or reproduced by injection of hypertonic saline ${ }^{11,12}$ into the facet joints, and maps of the pain distribution illustrated the overlap among several dermatome levels. This finding corresponds to the known anatomy, as each facet joint is innervated by small medial branches of the primary ramus from the dorsal root ganglion. Each joint receives innervation from at least 2 spinal levels, including the branch at the level of the named facet joint and a portion from the adjacent level. ${ }^{13}$ When the facets become pain generators, it is unusual that a single joint is involved. Bilateral involvement has been reported in $\leq 70 \%$ of cases and includes $\geq 3$ regional joints in many patients. ${ }^{14-16}$

There has been increasing scrutiny during the past 10 years regarding the efficacy and cost of chronic low back and neck pain evaluation and treatment, given their prevalence in society and the impact on the health care system. ${ }^{17}$ The increasing prevalence of pain relief procedures performed by anesthesiologists, pain management specialists, radiologists, and spine surgeons, among others, ${ }^{18}$ has drawn the attention of regulatory agencies and societies, resulting in a growing body of evidence-based reviews and practice guidelines. ${ }^{19-26}$ Controversy persists regarding intervention type, frequency, medication used, and total number of injections. These reviews, however, have served to confirm that there is an increasing demand for more controlled trials and outcome data for these patients and procedures, to justify imaging and imageguided interventions.

From the Department of Radiology (J.L.B.), UCSD Medical Center, San Diego, California; and Departments of Radiology and Anesthesia (W.H.W.W.), Center for Pain Medicine, UCSD Medical Center, San Diego, California.

Please address correspondence to Julie L. Bykowski, MD, Department of Radiology, University of California, San Diego, 3855 Health Sciences Drive, MC 0846, La Jolla, CA 92093; e-mail: jbykowski@ucsd.edu

Indicates open access to non-subscribers at www.ajnr.org

http://dx.doi.org/10.3174/ajnr.A2696

\section{Patient Evaluation}

Radiologists are often confronted with a nonspecific or incomplete history when interpreting radiographs, CT scans, and MR images of patients with low back pain or neck pain. Facet syndrome has been characterized as low back pain with unilateral radiation to the buttock and/or posterolateral thigh, which may be exacerbated in extension and relieved with flexion. Facet joint pain is often worse after periods of immobilization and improves with motion. Hyperextension and the tilt test can elicit symptoms on examination. Direct pressure over the facet joint during fluoroscopic correlation can also be helpful for isolating symptomatic levels.

Radiographically, the facet joints are best evaluated on oblique projections to avoid superimposed structures. ${ }^{27} \mathrm{CT}$ is more sensitive for evaluation and may reveal degenerative abnormalities such as osteophyte formation, hypertrophy of articular processes, articular cartilage thinning, vacuum joint phenomenon, or calcification of the joint capsule. ${ }^{28}$ Osteophyte production, joint space narrowing, and fluid within the facet joint can also be evaluated on MR imaging. ${ }^{29-31}$ Degenerative changes increase with age, ${ }^{32,33}$ and the above findings are less common in adults younger than 45 years of age. ${ }^{29,34}$ Many grading systems have been proposed ${ }^{27,29,35,36}$; however, the severity of imaging findings have not been shown to be specific or to correlate with the severity of symptoms, ${ }^{37,38}$ and the presence of any imaging abnormality should be correlated with the patient's examination and symptoms.

While imaging findings are not sensitive or specific, imaging does serve an important role in the evaluation of nonradicular spinal pain to exclude confounding processes such as infection, neoplasm, compression fracture, disk disease, or an associated entity such as a synovial cyst, which would require an alternative therapy.

Diagnostic image-guided medial branch nerve blocks have the most convincing evidence (level I) for isolating the facet joint as a pain generator, despite ongoing debate regarding the need for staged serial blocks or placebo-controlled blocks before proceeding to interventional therapy. ${ }^{39}$ To perform the diagnostic block, the patient should first be examined to establish a baseline pain level. The facet joint is identified fluoroscopically with a C-arm system, and the overlying skin is marked, prepped, and draped in usual sterile fashion. Lidocaine is used to anesthetize the skin and subcutaneous tissues. A 22-ga spinal needle is then inserted percutaneously and advanced under fluoroscopic guidance by using dorsal, lateral, and oblique projections to the junction of the superior artic- 

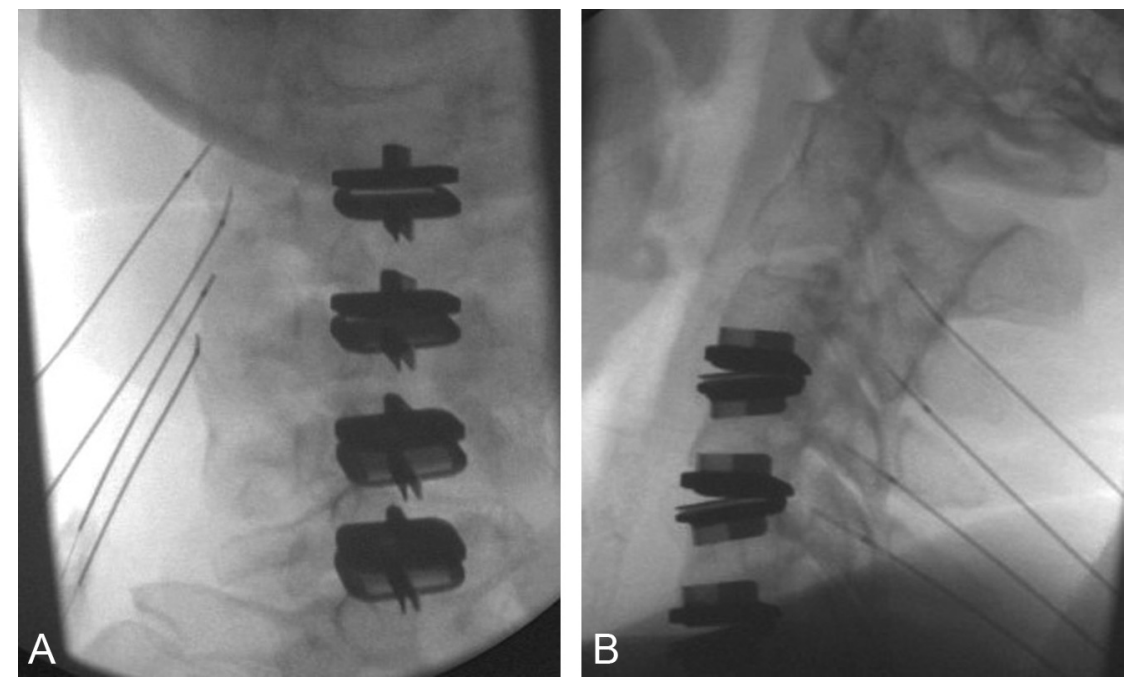

Fig 1. The left C2-3, C3-4, C4-5, and C5-6 facet joints are fluoroscopically identified in orthogonal planes, with the patient prone, for diagnostic medial branch nerve blocks. The patient had prior cervical disk replacements. Frontal projection $(A)$ confirms proper needle placement at the lateral aspect of the facet joints, and the lateral projection $(B)$ confirms the appropriate depth.

ular process and the transverse process for the lumbar spine. For the cervical spine, the anatomic target is the midpoint of the lateral margin of the facet (Fig 1). The exception would be when targeting the third occipital nerve, which is situated along the inferior margin of the $\mathrm{C} 2$ facet, adjacent to the $\mathrm{C} 2-3$ facet joint. Aspiration should be performed, with no return, before injection of a small volume $(0.2 \mathrm{~mL})$ of $2 \%$ lidocaine. The patient is then re-examined after a 20 -minute interval to assess response to the block.

The response to medial branch blocks has been reported to correlate with treatment outcome, despite confounding factors such as psychological comorbidities ${ }^{40}$; however, given the rate of reported false-positive blocks, placebo controls ${ }^{41,42}$ have been advocated before progressing to rhizotomy.

\section{Image-Guided Therapy}

Facet joint interventions may be considered in patients with $>3$ months of persistent nonradicular axial spine pain or cer- vicogenic headache, resulting in functional disability and not responding to conservative medical management or physical therapy. ${ }^{39}$

\section{Intra-Articular Facet Joint Injection}

Mooney and Robertson ${ }^{12}$ first described facet injections of a mix of steroid and anesthetic in 1976 as a pain relief technique. Case series since that time span the range of results, with good response to injections of steroids ${ }^{43-46}$ or hyaluronic acid $^{47}$ for lumbar facet disease, as well as no significant response compared with placebo sham injections. ${ }^{48,49}$ A paucity of literature reporting outcomes from intra-articular cervical facet injections limits conclusions regarding their broad-based effectiveness. ${ }^{50}$

Access to the facet joint can be performed with fluoroscopic (Fig 2) or CT guidance (Fig 3). Fluoroscopy affords the benefit of real-time feedback and multiplanar correlation and, in experienced hands, can minimize radiation dose to the pa-
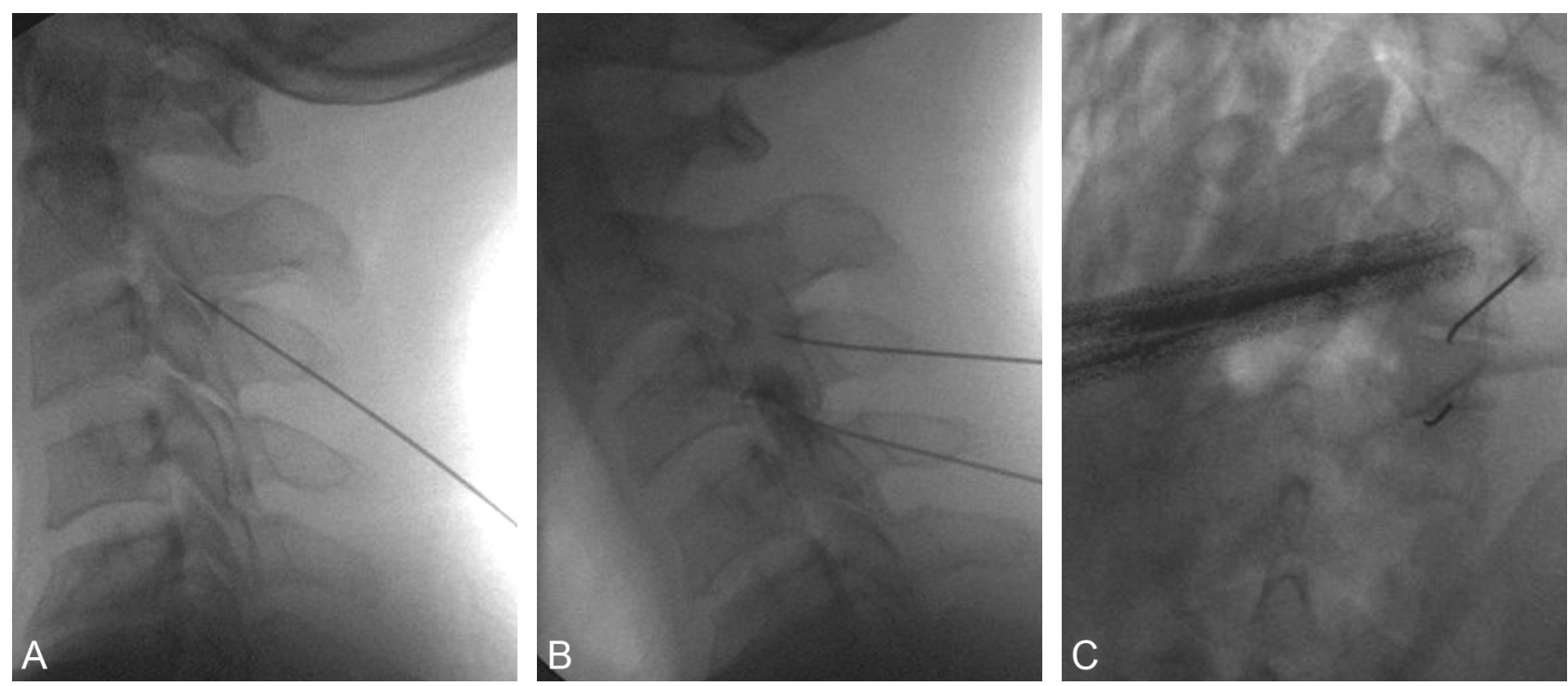

Fig 2. Fluoroscopic guidance is used for cervical facet intra-articular injection in a patient with chronic nonradicular neck pain and C2-5 facet joint tenderness. The pain was refractory to medial branch nerve ablation 9 months prior. The right C2-3 and C-4 facet joints are identified, and 3.6-inch 22-ga spinal needles are advanced with fluoroscopic guidance in lateral $(A)$, dorsal $(B)$, and oblique projections. $C$, A test injection of contrast confirms the appropriate placement and excludes vascular access, before injection of steroid and anesthetic. 

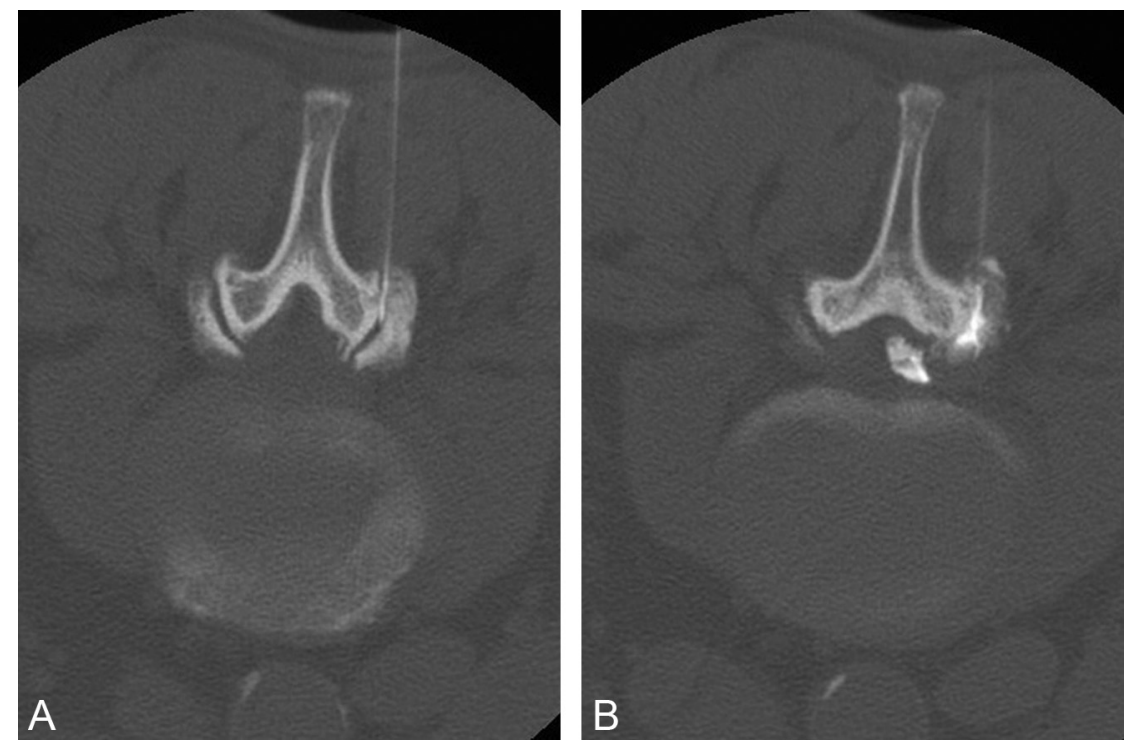

Fig 3. A, A 3.5-inch 22-ga spinal needle is advanced into the right $L 4-5$ facet under intermittent CT guidance, with the patient prone. $B$, Injection of $0.2 \mathrm{~mL}$ of contrast confirms placement in the joint, and epidural extension is seen after continuing contrast injection. Note that the images are displayed with the patient's right side on the right side of the image, rather than by radiologic convention. We find this orientation easier when performing procedures, especially in the situation of planned bilateral access.

tient. CT guidance requires access to the scanner; however, it can be instrumental for success in accessing joints with steep angles or large overhanging osteophytes. Once the target is identified with the appropriate imaging technique, the overlying skin is marked, prepped, and draped in a sterile fashion, and the skin and subcutaneous tissues are anesthetized. Image guidance is then used to advance a 3.5-inch 22-ga spinal needle to the facet joint, and a small volume $(0.2 \mathrm{~mL})$ of contrast is used to confirm the position. We use iohexol (Omnipaque; GE Healthcare, Princeton, New Jersey) as a safety precaution, given its compatibility with intrathecal use. Once intra-articular access is confirmed, a combined solution of anesthetic and steroid can be injected. The most common long-acting steroids include methylprednisolone, triamcinolone, and betamethasone. As with all steroid injections, attention should be given to the total patient steroid dose during a 12-month period, especially in patients with insulin-dependent diabetes.

Recent reviews of available literature have concluded that facet joint steroid injections have limited (level III) evidence of benefit, ${ }^{51}$ are ineffective, or have no benefit. ${ }^{17}$ A Multisociety Task Force comprising representation from the North American Spine Society, the International Spine Intervention Society, the American Society of Anesthesiologists, the American Academy of Pain Medicine, the American Academy of Physical Medicine and Rehabilitation, the Society of Interventional Radiology, the American Association of Neurologic Surgeons, the Congress of Neurologic Surgeons, the American College of Radiology, the American Society of Spine Radiology, the American Society of Neuroradiology, and the American Academy of Orthopedic Surgeons concluded that 1 therapeutic facet joint injection, per level affected, per year is reasonable if the patient has $>50 \%$ sustained relief for $>3$ months and RFA is contraindicated or refused by the patient. ${ }^{52}$ Intra-articular facet steroid injections may also be considered in patients with prior posterior fusion, in whom access to both medial branch nerves that supply a given level is limited by hardware or bone graft material.

\section{Medial Branch Nerve Ablation}

Given at least $50 \%$ pain relief in response to medial branch anesthetic blocks, RFA of the medial branch nerve may be considered. A Cochrane Review in $2003^{53}$ found only 3 highquality randomized controlled trials evaluating RFA of medial branch nerves as therapy for lumbar facetogenic pain. ${ }^{54-56}$ Evaluation and conclusions were limited due to the small overall number of patients treated and variations in the diagnostic block method and assessment, outcome assessment, and follow-up duration. Two studies that used comparative placebo blocks demonstrated positive response ( $>50 \%$ relief) at $4-8$ weeks ${ }^{54,55}$ based on functional and pain perception scales, while $1^{56}$ found no difference in outcomes of the treatment-versus-placebo group at 3 months. Fewer data exist for RFA as a treatment for cervical facet pain. Lord et $\mathrm{al}^{41}$ demonstrated the efficacy of RFA in a double-blind placebo-controlled trial in patients with whiplash injury after motor vehicle crashes, with success defined as a prolonged time of return of pain (median, 8 months) compared with a placebo.

Since then, additional small randomized trials of patients with chronic low back pain who responded positively to diagnostic blocks have been performed. van Wijk et al ${ }^{57}$ conducted a trial of 81 patients, randomized to radio-frequency treatment or placebo arms. Outcomes assessed at 3 months showed no difference between the groups, though $27 \%-29 \%$ of patients in each group reported improvement in perceived pain during the observation time. Nath et $\mathrm{al}^{58}$ required a response to 3 separate diagnostic blocks as an inclusion criterion. Of the 20 patients treated with multiple radio-frequency lesions at each symptomatic level, 6-month pain-perception scores and range of motion were significantly improved compared with those in the placebo group. A multicenter trial performed for cost-effectiveness randomized patients directly to RFA based on examinations or after a positive response to 1 or 2 comparative diagnostic blocks. ${ }^{59}$ Of the 84 patients treated, a higher percentage of success was found in the group that did not undergo diagnostic blocks. 

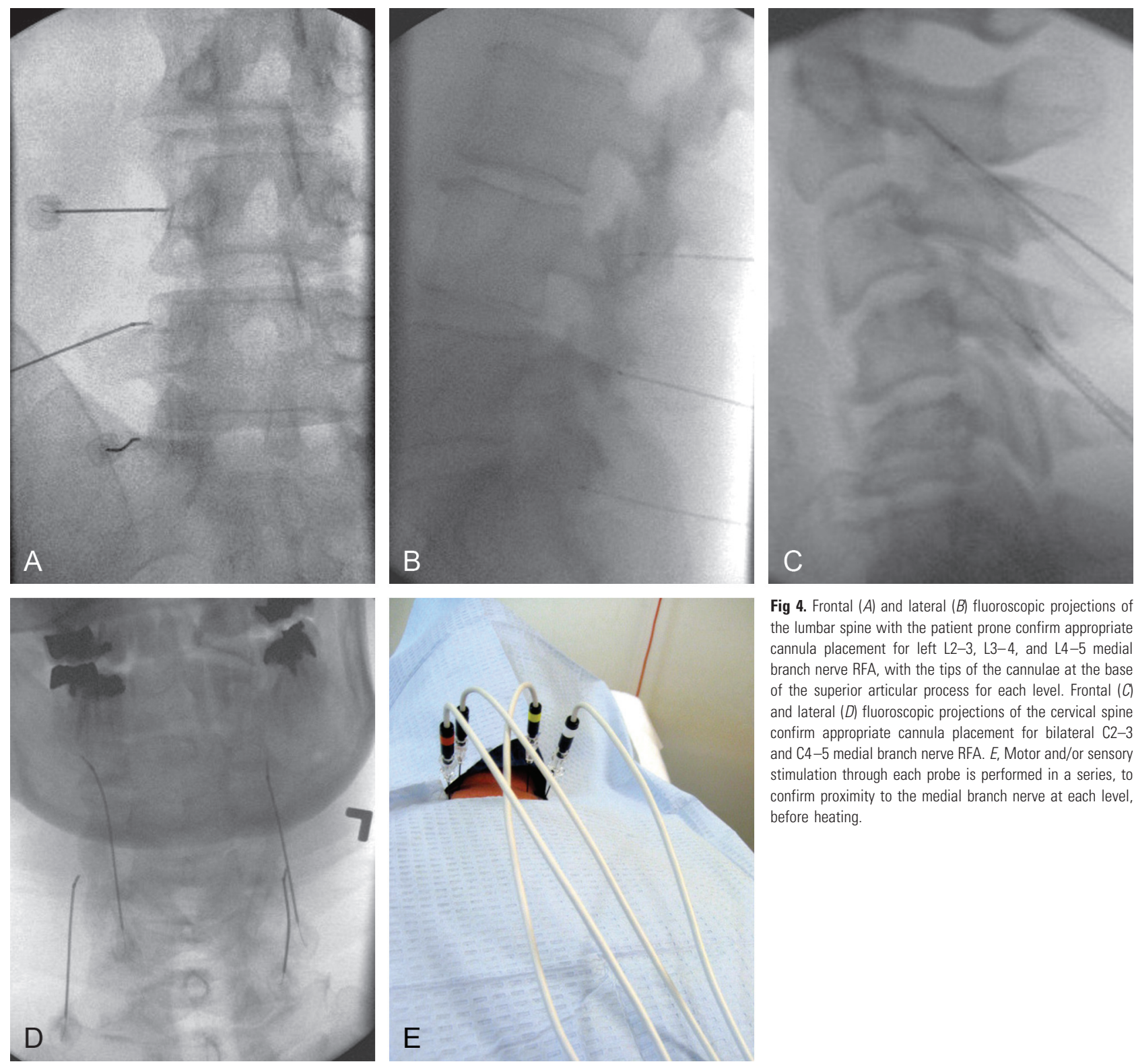

Fig 4. Frontal $(A)$ and lateral $(B)$ fluoroscopic projections of the lumbar spine with the patient prone confirm appropriate cannula placement for left L2-3, L3-4, and L4 -5 medial branch nerve RFA, with the tips of the cannulae at the base of the superior articular process for each level. Frontal $(C)$ and lateral $(D)$ fluoroscopic projections of the cervical spine confirm appropriate cannula placement for bilateral C2-3 and $\mathrm{C} 4-5$ medial branch nerve RFA. $E$, Motor and/or sensory stimulation through each probe is performed in a series, to confirm proximity to the medial branch nerve at each level, before heating.

Overall outcomes showed a $64 \%$ positive response at 1 month and $43 \%$ at 3 months, with $>50 \%$ relief considered as success. Gofeld et $\mathrm{al}^{60}$ conducted a 10 -year prospective audit including 174 patients who had responded to comparative diagnostic blocks. One hundred nineteen patients $(68 \%)$ had good $(>50 \%)$ to excellent $(>80 \%)$ pain relief lasting 6-24 months; 55 (32\%) experienced no benefit from the procedure.

For the procedure, the patient is placed prone and the appropriate levels are identified fluoroscopically. The overlying skin is marked, prepped, and draped in the usual sterile fashion. Lidocaine is used for local anesthesia of the skin and soft tissues, and patients are offered moderate sedation and are monitored by nursing throughout the procedure. At each level, a 22 -ga 5 - to $15-\mathrm{cm}$ insulated 5 - to $10-\mathrm{mm}$ active-tip radio-frequency cannula is inserted percutaneously and advanced under fluoroscopic guidance by using dorsal, lateral, and oblique projections to the base of the superior articular process, the location of the respective medial branch nerves between the intervertebral foramen and the mamilloaccessory ligament at the lumbar levels. Cervical-level targeting is identical to that in the medial nerve block procedure previously described. Aspiration is performed to exclude return of blood or CSF or inducible paresthesia. Needle placement is also confirmed with motor and/or sensory stimulation.

The needles are then injected using a mixture of preservative-free $2 \%$ lidocaine and steroid at each level to provide local analgesia during the heating process. Some operators favor dexamethasone in the cervical and thoracic regions, to minimize any risk of particulate-related embolism. The radio-frequency probes are then inserted through the needles and heated in serial fashion either in the radio-frequency mode $\left(80^{\circ} \mathrm{C}\right.$ for 1.5 minutes) or pulsed mode at $\left(42^{\circ} \mathrm{C}\right.$ for 2 minutes $)$ (Fig 4). After the heating cycle has finished, the needles are removed and sterile bandages are applied. Postprocedural examination and postsedation monitoring are performed and documented. Complications are rare and include bleeding, infection, or incomplete pain relief. 

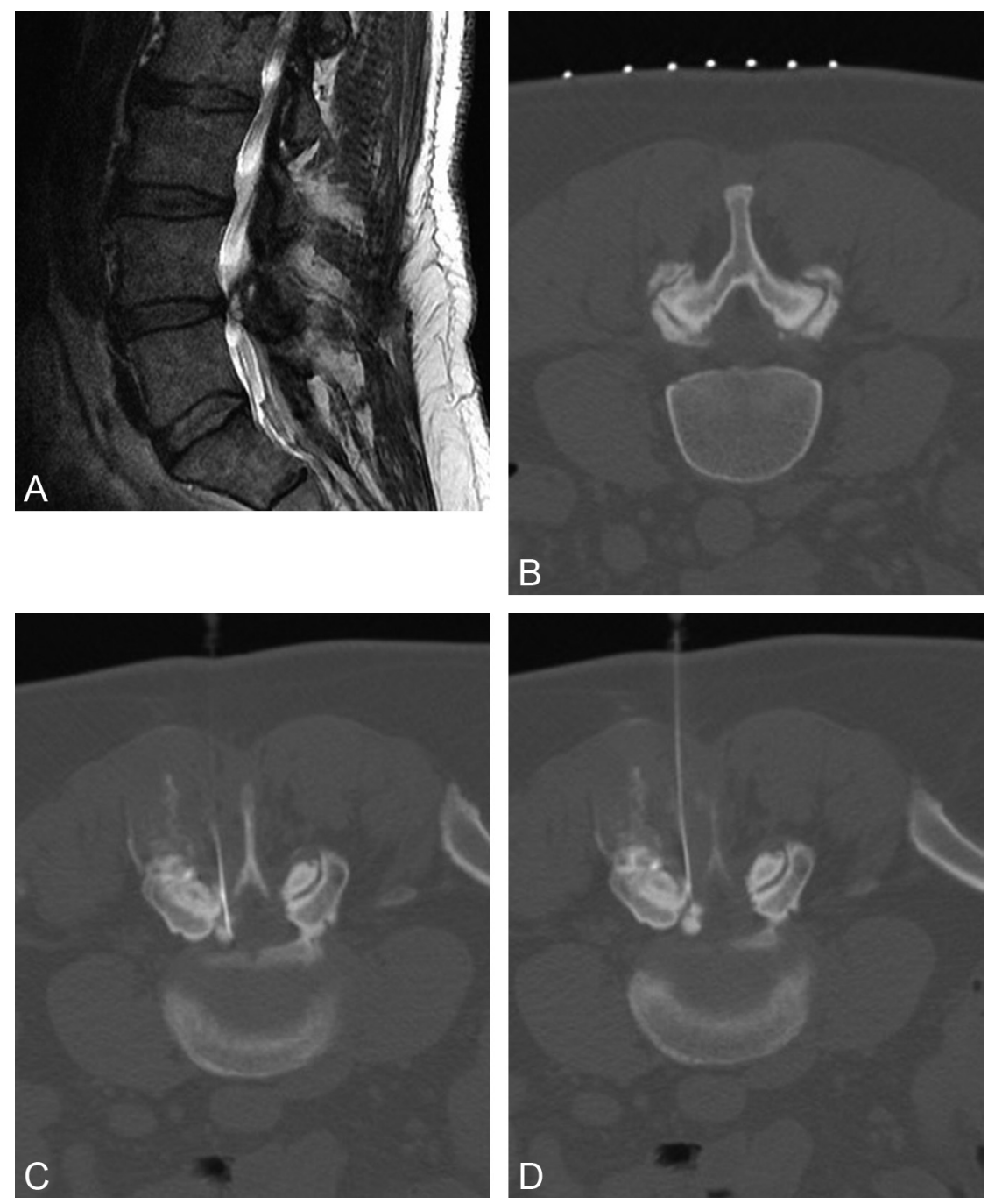

Fig 5. A, Sagittal T2-weighted MR image reveals a large left $L 4-5$ synovial cyst causing moderate central canal stenosis and compression of the exiting left $L 4$ nerve root, corresponding to the patient's radicular symptoms and neuroclaudication episodes. $B$, CT is used to localize the facet and reveals large overhanging osteophytes limiting joint access. $C$, CT guidance is then used for a left sublaminar approach. $D$, Rapid forceful injection of contrast into the cyst is performed; epidural spread of contrast confirms cyst rupture. The patient's pain scale was $8 / 10$ preprocedure and 2/10 postprocedure.

The suggested retreatment interval is $6-12$ months or longer as tolerated, with reports of relief continuing after serial treatments. ${ }^{61}$ Accelerated repeat RFA treatments may be considered in the setting of recurrent injury or cervicogenic headache. ${ }^{62}$

With increasing attention on outcomes and the cost-effectiveness of therapy, discussion continues regarding how to best identify patients who will benefit and whether the cost and time required for multiple and/or placebo-controlled diagnostic blocks translates into better patient selection or may exclude patients from receiving beneficial therapy. ${ }^{59}$ Additionally, debate continues over what constitutes success: Is it $50 \%, 80 \%$, or $100 \%$ relief, $^{63}$ and what duration? These studies have demonstrated the importance of clearly documenting pretreatment and posttreatment pain perception, functional assessment, and analgesic/opiate requirements.

\section{CT-Guided Decompression of Synovial Cysts}

Synovial cysts have been associated with radicular and neuroclaudication symptoms, based on their location, size, and compression of adjacent structures. They also can be an incidental asymptomatic finding on lumbar MR imaging. Because the cyst communicates with the affected facet synovial joint, these lesions can be easily accessed percutaneously with imaging guidance of the needle into the facet joint, though direct puncture of cysts via a sublaminar approach can also be performed (Fig 5). Given the concomitant osteoarthritic changes, CT guidance is often preferred over fluoroscopy to access the joint.

When positioning the patient on the scanner table, it is often helpful to place pillows under the lower abdomen and pelvis, to increase the angle of the target joints rather than relying on angling the gantry alone. Access to the joint is obtained in the same manner as that in an intra-articular injection. A mixture of steroid, anesthetic, and contrast is injected into the joint space, with the goal of rapid expansion resulting in cyst rupture. Success is confirmed by epidural spread of contrast (Fig 6). Accordingly, the anesthetic and steroid in the injectant may help reduce periprocedural inflammation. Serial reports have confirmed the efficacy of this therapy, which 

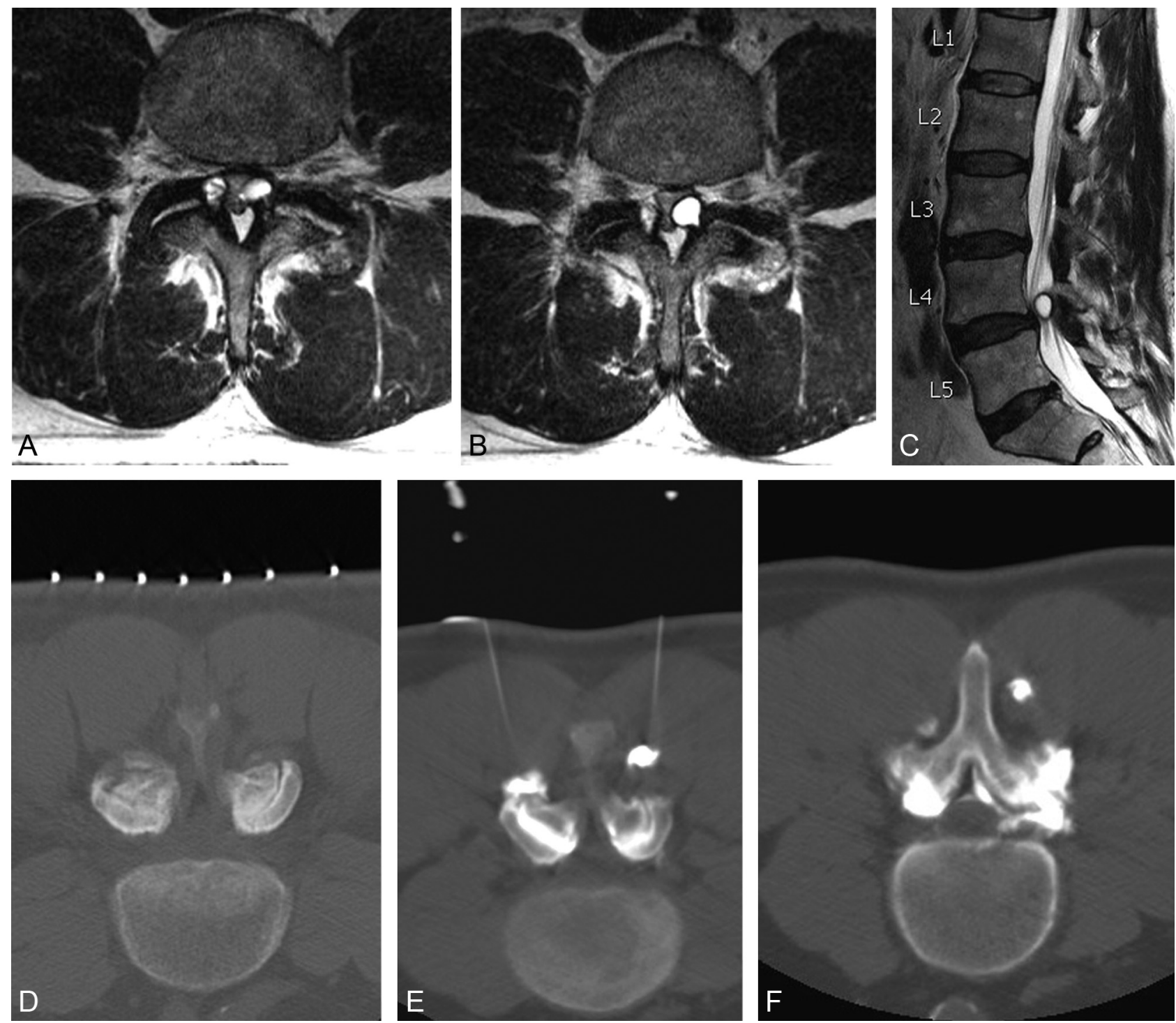

Fig 6. Axial $(A$ and $B)$ and sagittal (C) T2-weighted MR images reveal synovial cysts at $L 4-5$ bilaterally, causing severe central canal stenosis in a patient with neuroclaudication symptoms. A small tail is seen extending from the posterolateral aspect of the left synovial cyst to the left $L 4-5$ facet joint $(B)$, with associated degenerative changes of the facet joint. $D$, Two 22-ga 3.5-inch spinal needles are advanced with CT guidance into the posterior aspect of the L4-5 facet joints bilaterally, and a test injection of contrast confirms appropriate access to each joint, respectively. E, After forceful injection of contrast mixed with steroid, epidural extension of contrast material is seen, confirming cyst rupture. Contrast extravasation is also noted along the needle trajectory, $(F$.

may delay or obviate surgical resection of the cysts. ${ }^{64-67}$ The patient's pain level should be re-assessed within 20 minutes of completing the procedure, to confirm relief from the intervention.

\section{Emerging Percutaneous Image-Guided Interventions}

Open pedicle screw fixation has been a common adjunct stabilizing measure with surgical intervertebral body fusion procedures; however, it requires muscle dissection, with related postprocedure morbidity and chronic scarring. Accordingly, percutaneous or minimally invasive methods for transfacet fixation have been desired, and biomechanical and cadaver models have been performed for proof of concept. ${ }^{68-71}$ Percutaneous innovations for facet screw fixation with hardware $^{72,73}$ or bone allograft $(\text { Fig } 7)^{74}$ have now reached the market, and technical notes regarding $\mathrm{CT}^{75}$ and fluoroscopic ${ }^{72,76}$ guidance have been reported in small series. Concerns have been expressed about the use of facet fixation as an independent procedure in the outpatient setting, rather than as an adjunct to lumbar interbody fixation, as well as about complications from bone allograft dowel migration. Insufficient independent data are available to assess the safety, efficacy, or outcomes of these procedures. ${ }^{77}$

\section{Conclusions}

Neuroradiologists need to be aware of the role of facet joints as a possible independent or contributory pain generator in the evaluation of patients with chronic low back pain. While imaging findings are not specific to implicate the facet joints, imaging is extremely useful to exclude nondegenerative pain etiologies as well as to identify confounding entities such as synovial cysts, which would have treatment implications. Fluoroscopically guided medial branch nerve blocks are emerging as a standard of care to confirm the facet joint as a pain gen- 

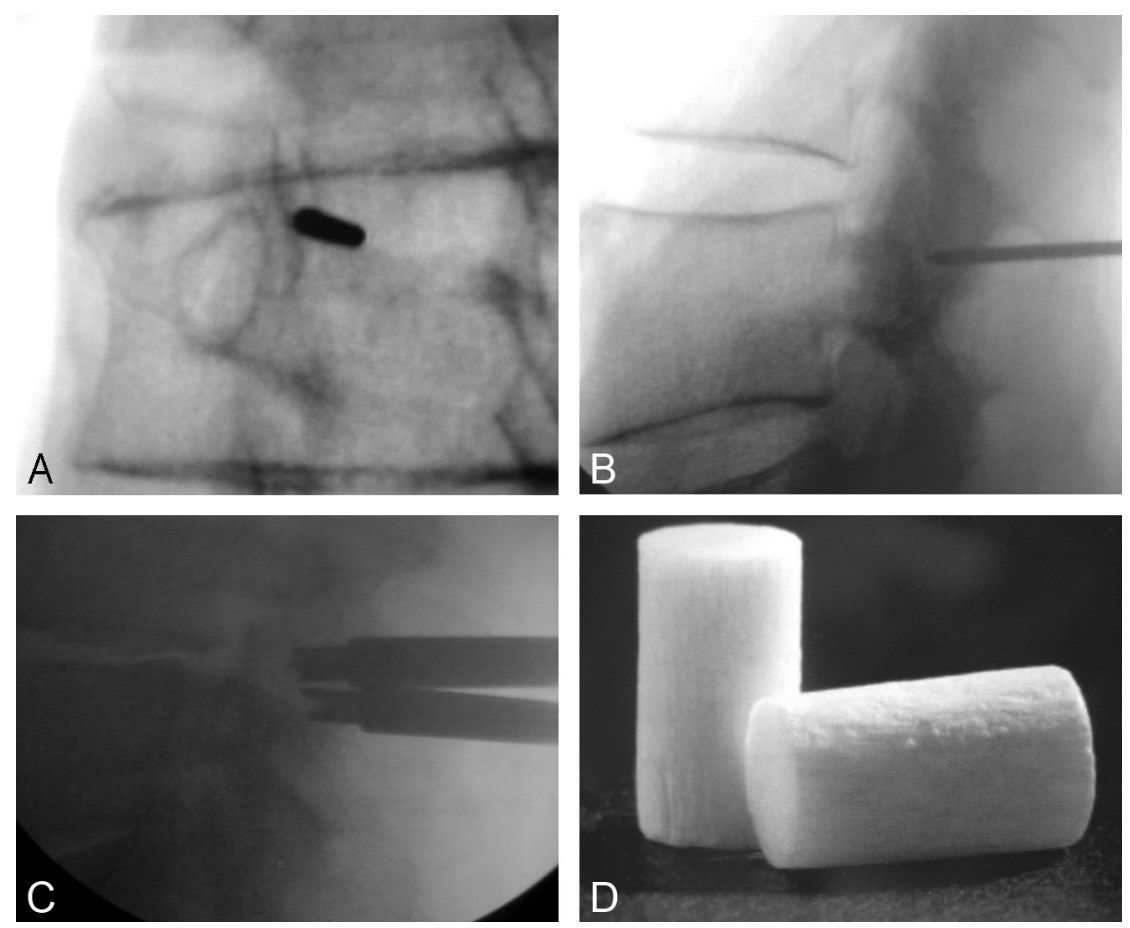

Fig 7. Frontal $(A)$ and lateral $(B)$ projections confirm the appropriate trajectory for the guide pin extending to the facet joint. A small incision is then made in the skin, and the spatula and drill devices are sequentially advanced into the facet joint to form the appropriate cavity. The tamping device is then advanced $(C)$ to seat the dowel of bone allograft material $(D)$. Note that the allograft is difficult to see under fluoroscopic guidance $(C)$. Image $D$ provided courtesy of Trufuse (Clearwater, Florida).

erator and to isolate the appropriate levels. These can be followed by thermal ablation of the medial branch nerve under fluoroscopic guidance; however, additional scrutiny of these procedures, the numbers of levels treated in a single visit, and the frequency of re-treatment remain areas of continued debate in the literature, with emphasis on outcomes research. Additional image-guided minimally invasive therapies such as percutaneous facet fixation are emerging, though they have not been performed in sufficient numbers to understand longterm efficacy or complications. Neuroradiologists interested in treating patients with chronic facet degenerative pain should be aware of the options and the role of physical examination and history in addition to imaging, as well as the need to closely track and report outcomes.

\section{References}

1. Abel MS. The unstable apophyseal joint: an early sign of lumbar disc disease. Skeletal Radiol 1977;2:31-37

2. Oppenheimer A. Diseases of the apophyseal (intervertebral) articulations. J Bone Joint Surg 1938;20:285-313

3. Lewin T. Osteoarthritis in lumbar synovial joints. Acta Orthop Scand 1964;73:1-112

4. Cavanaugh JM, Ozaktay AC, Yamashita HT, et al. Lumbar facet pain: biomechanics, neuroanatomy and neurophysiology. J Biomech 1996;29:1117-29

5. Igarashi A, Kikuchi S, Konno S, et al. Inflammatory cytokines released from the facet joint tissue in degenerative lumbar spinal disorders. Spine 2004;29:2091-95

6. Boswell MV, Singh V, Staats PS, et al. Accuracy of precision diagnostic blocks in the diagnosis of chronic spinal pain of facet or zygapophysial joint origin: a systematic review. Pain Physician 2003;6:449-56

7. Sehgal N, Dunbar EE, Shah RV, et al. Systematic review of diagnostic utility of facet (zygapophysial) joint injections in chronic spinal pain: an update. Pain Physician 2007;10:213-28

8. Bogduk N. International Spinal Injection Society guidelines for the performance of spinal injection procedures. Part 1. Zygapophysial joint blocks. Clin J Pain 1997;13:285-302

9. Yin $\mathrm{W}$, Bogduk N. The nature of neck pain in a private pain clinic in the United States. Pain Med 2008;9:196-203
10. Manchikanti L, Manchikanti K, Pampati V, et al. The prevalence of facet jointrelated chronic neck pain in postsurgical and non-postsurgical patients: a comparative evaluation. Pain Pract 2008;8:5-10

11. Hirsch C, Ingelmark BE, Miller M. The anatomical basis for low back pain: studies on the presence of sensory nerve endings in ligamentous, capsular and intervertebral disc structures in the human lumbar spine. Acta Orthop Scand 1963;33:1-17

12. Mooney V, Robertson J. The facet syndrome. Clin Orthop 1976;115:149

13. Pedersen HE, Blunck CFJ, Gardner E. Anatomy of lumbosacral posterior rami and meningeal branches of spinal nerves (sinuvertebral nerves) with experimental study of their functions. J Bone Joint Surg 1956;38A:377-91

14. Manchikanti L, Boswell MV, Singh V, et al. Prevalence of facet joint pain in chronic spinal pain of cervical, thoracic, and lumbar regions. BMC Musculoskelet Disord 2004;5:15

15. Manchikanti L, Singh V, Pampati V, et al. Is there correlation of facet joint pain in lumbar and cervical spine? An evaluation of prevalence in combined chronic low back and neck pain. Pain Physician 2002;5:365-71

16. Manchukonda R, Manchikanti KN, Cash KA, et al. Facet joint pain in chronic spinal pain: an evaluation of prevalence and false-positive rate of diagnostic blocks. J Spinal Disord Tech 2007;20:539-45

17. Chou R, Huffman L. Guideline for the evaluation and management of low back pain: evidence review. American Pain Society. 2009. www.ampainsoc.org/ pub/pdf/LBPEvidRev.pdf. Accessed July 25, 2011

18. Carrino JA, Morrison WB, Parker L, et al. Spinal injection procedures: volume, provider distribution, and reimbursement in the U.S. Medicare population from 1993 to 1999. Radiology 2002;225:723-29

19. Staal JB, de Bie R, de Vet HC, et al. Injection therapy for subacute and chronic low-back pain. Cochrane Database Syst Rev 2008:CD001824

20. Staal JB, de Bie RA, de Vet HC, et al. Injection therapy for subacute and chronic low back pain: an updated Cochrane Review. Spine (Phila $\mathrm{Pa}$ 1976) 2009;34:49-59

21. Chou R, Qaseem A, Snow V, et al, and the Clinical Efficacy Assessment Subcommittee of the American College of Physicians: American Pain Society Low Back Pain Guidelines Panel. Diagnosis and treatment of low back pain: a joint clinical practice guideline from the American College of Physicians and the American Pain Society. Ann Intern Med 2007;147:478-91

22. Airaksinen O, Brox JI, Cedraschi C, et al, for the COST B13 Working Group on Guidelines for Chronic Low Back Pain. Chapter 4. European guidelines for the management of chronic nonspecific low back pain. Eur Spine J 2006;15(suppl 2):S192-300

23. US Department of Health and Human Services. Centers for Medicare and Medicaid Services. CMS Manual System. Facet Joints. Transmittal \#440. Publication \#100-20. 2009. www.cms.hhs.gov/transmittals/downloads/R440OTN.pdf. Accessed July 25, 2011 
24. Boswell MV, Trescot AM, Datta S, et al. Interventional techniques: evidencebased practice guidelines in the management of chronic spinal pain. Pain Physician 2007;10:7-111

25. Bogduk N. An algorithm for the investigation of low back pain. In: International Spine Intervention Society. Practice Guidelines for Spinal Diagnostic and Treatment Procedures. Chicago: International Spine Intervention Society; 2004:87-94

26. Bogduk N. An algorithm for the conduct of cervical synovial joint blocks. In: International Spine Intervention Society. Practice Guidelines for Spinal Diagnostic and Treatment Procedures. Chicago: International Spine Intervention Society; 2004:152-60

27. Pathria M, Sartoris DJ, Resnick D. Osteoarthritis of the facet joints: accuracy of oblique radiographic measurement. Radiology 1987;164:227-30

28. Carrera GF, Haughton VM, Syvertsen A, et al. Computed tomography of the lumbar facet joints. Radiology 1980:134:145-48

29. Fujiwara A, Tamai K, Yamato M, et al. The relationship between facet joint osteoarthritis and disc degeneration of the lumbar spine: an MRI study. Eur Spine J 1999;8:396-401

30. Rihn JA, Lee JY, Khan M, et al. Does lumbar facet fluid detected on magnetic resonance imaging correlate with radiographic instability in patients with degenerative lumbar disease? Spine 2007;32:1555-60

31. Chaput C, Padon D, Rush J, et al. The significance of increased fluid signal on magnetic resonance imaging in lumbar facets in relationship to degenerative spondylolisthesis. Spine 2007;32:1883-87

32. Eubanks JD, Lee MJ, Cassinelli E, et al. Prevalence of lumbar facet arthrosis and its relationship to age, sex, and race: an anatomic study of cadaveric specimens. Spine 2007;32:2058-62

33. Lee MJ, Riew KD. The prevalence of cervical facet arthrosis: an osseous study in a cadaveric population. Spine J 2009;9:711-14

34. Weishaupt D, Zanetti M, Hodler J, et al. MR imaging of the lumbar spine: prevalence of intervertebral disk extrusion and sequestration, nerve root compression, end plate abnormalities, and osteoarthritis of the facet joints in asymptomatic volunteers. Radiology 1998;209:661-66

35. Weishaupt $\mathrm{D}$, Zanetti M, Boos N, et al. MR imaging and CT in osteoarthritis of the lumbar facet joints. Skeletal Radiol 1999;28:215-19

36. Kettler A, Wilke HJ. Review of existing grading systems for cervical or lumbar disc and facet joint degeneration. Eur Spine J 2006;15:705-18

37. Kalichman L, Li L, Kim DH, et al. Facet joint osteoarthritis and low back pain in the community-based population. Spine 2008;33:2560-65

38. Schwarzer AC, Aprill CN, Derby R, et al. Clinical features of patients with pain stemming from the lumbar zygapophysial joints. Spine 1994;19:1132-37

39. Manchikanti L, Helm S, Singh V, et al. An algorithmic approach for clinical management of chronic spinal pain. Pain Physician 2009;12:E225-64

40. Manchikanti L, Pampati V, Bakhit CE, et al. Effectiveness of lumbar facet joint nerve blocks in chronic low back pain: a randomized clinical trial. Pain Physician 2001;4:101-17

41. Lord SM, Barnsley L, Wallis BJ, et al. Percutaneous radiofrequency neurotomy for chronic cervical zygapophyseal-joint pain. N Engl J Med 1996;335:1721-26

42. Bogduk N. On diagnostic blocks for lumbar zygapophysial joint pain. F1000 Med Rep 2010;2:57

43. Lynch MC, Taylor JF. Facet joint injection for low back pain: a clinical study. J Bone Joint Surg 1986;68:138-41

44. Meleka S, Patra A, Minkoff E, et al. Value of CT fluoroscopy for lumbar facet blocks. AJNR Am J Neuroradiol 2005;26:1001-03

45. Dolan AL, Ryan PJ, Arden NK, et al. The value of SPECT scans in identifying back pain likely to benefit from facet joint injection. $\mathrm{Br} J$ Rheumatol 1996;35:1269-73

46. Pneumaticos SG, Chatziioannou SN, Hipp JA, et al. Low back pain: prediction of short-term outcome of facet joint injection with bone scintigraphy. Radiology 2006;238:693-98

47. Fuchs S, Erbe T, Fischer HL, et al. Intraarticular hyaluronic acid versus glucocorticoid injections for nonradicular pain in the lumbar spine. J Vasc Interv Radiol 2005; 16:1493-98

48. Carette S, Marcoux S, Truchon R, et al. A controlled trial of corticosteroid injections into facet joints for chronic low back pain. $N$ Engl J Med 1991;325:1002-07

49. Lilius G, Laasonen EM, Myllynen P, et al. Lumbar facet joint syndrome: a randomised clinical trial. J Bone Joint Surg 1989;71:681-84

50. Falco FJ, Erhart S, Wargo BW, et al. Systematic review of diagnostic utility and therapeutic effectiveness of cervical facet joint interventions. Pain Physician 2009; $12: 323-44$

51. Datta S, Lee M, Falco FJ, et al. Systematic assessment of diagnostic accuracy and therapeutic utility of lumbar facet joint interventions. Pain Physician 2009; $12: 437-60$

52. Hecker B, Waldmann G, Mangold W. Multisociety Facet Task Force Consensus Response. 2009. www.spine.org/Documents/task_force_facetFINAL.pdf. Accessed July 25, 2011

53. Niemistö L, Kalso E, Malmivaara A, et al. Radiofrequency denervation for neck and back pain: a systematic review within the framework of the Cochrane Collaboration Back Review Group. Spine 2003;28:1877-88

54. van Kleef M, Barendse GA, Kessels A, et al. Randomized trial of radiofrequency lumbar facet denervation for chronic low back pain. Spine 1999;24:1937-42

55. Gallagher J, Petriccione di Vadi PL, Wedley JR, et al. Radiofrequency facet joint denervation in the treatment of low back pain: a prospective controlled double-blind study to assess its efficacy. The Pain Clinic 1994;7:193-98

56. Leclaire R, Fortin L, Lambert R, et al. Radiofrequency facet joint denervation in the treatment of low back pain: a placebo-controlled clinical trial to assess efficacy. Spine 2001;26:1411-16

57. van Wijk RM, Geurts JW, Wynne HJ, et al. Radiofrequency denervation of lumbar facet joints in the treatment of chronic low back pain: a randomized, double-blind, sham lesion-controlled trial. Clin J Pain 2005;21:335-44

58. Nath S, Nath CA, Pettersson K. Percutaneous lumbar zygapophysial (facet) joint neurotomy using radiofrequency current, in the management of chronic low back pain: a randomized double-blind trial. Spine 2008;33:1291-97

59. Cohen SP, Williams KA, Kurihara C, et al. Multicenter, randomized, comparative cost-effectiveness study comparing 0,1 , and 2 diagnostic medial branch (facet joint nerve) block treatment paradigms before lumbar facet radiofrequency denervation. Anesthesiology 201:113:395-405

60. Gofeld M, Jitendra J, Faclier G. Radiofrequency denervation of the lumbar zygapophysial joints: 10-year prospective clinical audit. Pain Physician 2007;10:291-99

61. Rambaransingh B, Stanford G, Burnham R. The effect of repeated zygapophysial joint radiofrequency neurotomy on pain, disability, and improvement duration. Pain Med 2010;11:1343-47

62. Manchikanti L, Boswell MV, Singh V, et al. Comprehensive review of neurophysiologic basis and diagnostic interventions in managing chronic spinal pain. Pain Physician 2009;12:71-120

63. Manchikanti L, Pampati S, Cash KA. Making sense of the accuracy of diagnostic lumbar facet joint nerve blocks: an assessment of the implications of 50\% relief, $\mathbf{8 0 \%}$ relief, single block, or controlled diagnostic blocks. Pain Physician 2010;13:133-43

64. Allen TL, Tatli Y, Lutz GE. Fluoroscopic percutaneous lumbar zygapophyseal joint cyst rupture: a clinical outcome study. Spine J 2009;9:387-95

65. Liu SS, KD Williams, BP Drayer, et al. Synovial cysts of the lumbosacral spine: diagnosis by MR imaging. AJNR Am J Neuroradiol 1989;10:1239-42

66. Parlier-Cuau C, Wybier M, Nizard R, et al. Symptomatic lumbar facet joint synovial cysts: clinical assessment of facet joint steroid injection after 1 and 6 months and long-term follow-up in 30 patients. Radiology 1999;210:509-13

67. Martha JF, Swaim B, Wang DA, et al. Outcome of percutaneous rupture of lumbar synovial cysts: a case series of 101 patients. Spine J 2009;9:899-904

68. Sasso RC, Best NM, Potts EA. Percutaneous computer-assisted translaminar facet screw: an initial human cadaveric study. Spine J 2005;5:515-19

69. Su BW, Cha TD, Kim PD, et al. An anatomic and radiographic study of lumbar facets relevant to percutaneous transfacet fixation. Spine (Phila $\mathrm{Pa}$ 1976) 2009;34:E384-90

70. Mahar A, Kim C, Oka R, et al. Biomechanical comparison of a novel percutaneous transfacet device and a traditional posterior system for single level fusion. J Spinal Disord Tech 2006;19:591-94

71. Beaubien BP, Mehbod AA, Kallemeier PM, et al. Posterior augmentation of an anterior lumbar interbody fusion: minimally invasive fixation versus pedicle screws in vitro. Spine 2004;29:406-12

72. Shim CS, Lee SH, Jung B, et al. Fluoroscopically assisted percutaneous translaminar facet screw fixation following anterior lumbar interbody fusion: technical report. Spine 2005;30:838-43

73. Spineology. St. Paul, Minnesota. www.spineology.com. Accessed July 25, 2011

74. TruFuse. Clearwater, Florida. www.trufuse.com. Accessed July 25, 2011

75. Kang HY, Lee SH, Jeon SH, et al. Computed tomography-guided percutaneous facet screw fixation in the lumbar spine: technical note. J Neurosurg Spine 2007;7:95-98

76. Harris EB, Massey P, Lawrence J, et al. Percutaneous techniques for minimally invasive posterior lumbar fusion. Neurosurg Focus 2008;25:12

77. AANS Technical Assessment of Tru-Fuse 2009. http://www.aans.org/en/ Education\%20and\%20Meetings/Emerging\%20Technology/Technical\%20 Assessment\%20of\%20Tru-Fuse.aspx. Accessed July 20, 2011 